\title{
Study of Molecular Composition and Chemical Group Presents in Plants Extracts by Using Mass Spectrometry and FTIR
}

\author{
Efrain Eduardo Rizo Tafolla ${ }^{1}$, Dhananjay Tripathi ${ }^{2}$ and D. K. Tiwari ${ }^{3}$ \\ 1. Ingeniería Bioquímica, Instituto Tecnológico de La Piedad, La Piedad, Michoacán. \\ 2. CSIR-National Environmental Engineering Research Institute (NEERI), Nehru Marg, Nagpur, \\ Maharashtra, India. \\ 3. CONACYT-El Colegio de Michoacán/LADIPA, La Piedad, Michoacán México.
}

The importance of plants and avalible compounds are in highly demand for human consumption as well the medicial purposes. Most of the plants contains many banificial facts such as Anti-oxidant activity, herbal medicine and anti-inflammatory. Considering all these banifical facts and their demand in traditional as well comercial demads we have selected the Turmeric (Curcuma longa), Garlic (Genus allium) and Coffee (Coffea arabica). Theses plants are beneficial because of their Molecular composition and chemical group presents. In Turmeric rhizomes have been found to be a rich source of phenolic compounds, viz.curcuminoids, Curcuminoids [1]. In garlic had been found allinin, ajoene, diallylsulfide, B-vitamins, proteins, saponins, flavonoids and maillard reaction products [2]. The characteristic compound in coffee is caffeine. All of them give to each one the great health benefits.

The present study was conducted to identify those compounds that give health benefits. Especially alkaloids, amino acids and curcuminoids of plant extract. We want to identify them because they are molecules with amines, alcohol and methyl functional groups. We are interested on them. To accomplish this goal, we applied a rapid solvent extraction assisted by sonication. Ultrasonic Assisted Extraction (UAE) stands out as a sustainable alternative which requires a moderate investment of solvent and energy. Furthermore, it is easy to handle, safe, economical and reproducible [4].

Each plant had a specific preparation to be used with UAE. Garlic was dried at $80{ }^{\circ} \mathrm{C}$ by 4 hours. It was then crushed in a Micro-grinded with 4 marbles by 4 minutes. Turmeric was crushed in a blender by 30 seconds, several times. Coffee was crushed in a Micro-grinded with 4 marbles by 4 minutes. The methodology of UAE was the following, 15 grs of plant were added to $45 \mathrm{~mL}$ of solvent. Ethanol to garlic, Methanol to Turmeric and Dichloromethane to coffee. Then, the soltion was sonicated by 60 minutes at $60{ }^{\circ} \mathrm{C}$. Finally, the solution was centrifuged ( $5 \mathrm{~min}, 5000 \mathrm{rpm}$ ) and the resultant solution was collected and analyzed.

The analyses of the plant extract were performed by using FTIR (FTIR-ATR / Spectrometer Frontier of PerkinElmer) and the identification of molecules was with Mass Spectrometry (JMS-T100LP of JEOL). In FTIR, we looked for the functional groups available after the solvent extraction (figure 1). The first think we could observed was the better intensity of some picks and some new picks. Garlic extract got more intensity for amine group. It could be because the amino acids in garlic such as Valine, Alanine, Leucine and Phenylalanine (figure 2). Coffee extract had the best intensity for methyl group. It could be because the four-methyl group present in the molecule of caffeine found in mass spectrometry (figure 3 ). In Turmeric extract we found amine, alcohol and methyl groups. It could be because the molecules of curcumin and demethoxycurcumin found in mass spectrometry (figure 4). In table 1, there are all the molecules identified. 
In conclusion, UAE is possible to be use to obtain a mix of alkaloids, amino acids and curcuminoids. Mass spectrometry and FTIR are good nondestructive techniques to identify molecular composition and chemical group presents in Plants Extracts.

\section{References:}

[1] Rajesh et al, International Journal of Universal Pharmacy and Bio Sciences 2(2) (2013).

[2] Huzaifa et al, Report and Opinion 6(8) (2014).

[3] Medina-Torres et al, Agronomy 7 (2017), p. 47.

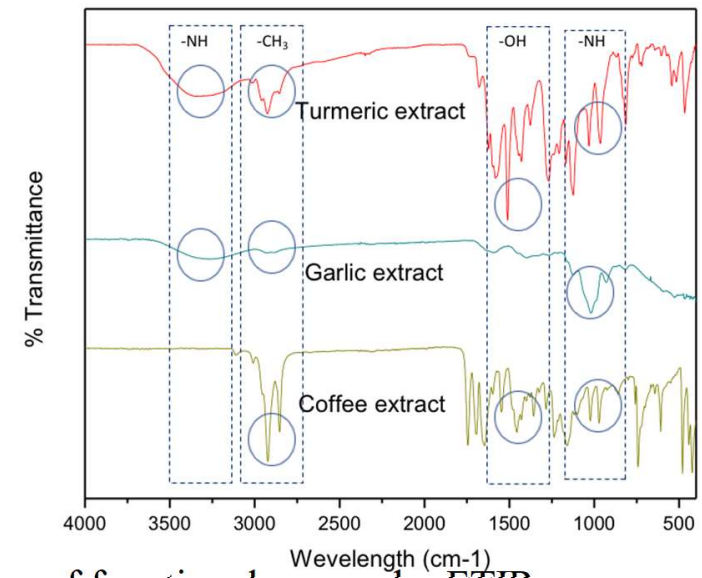

Figure 1. Identification of functional groups by FTIR

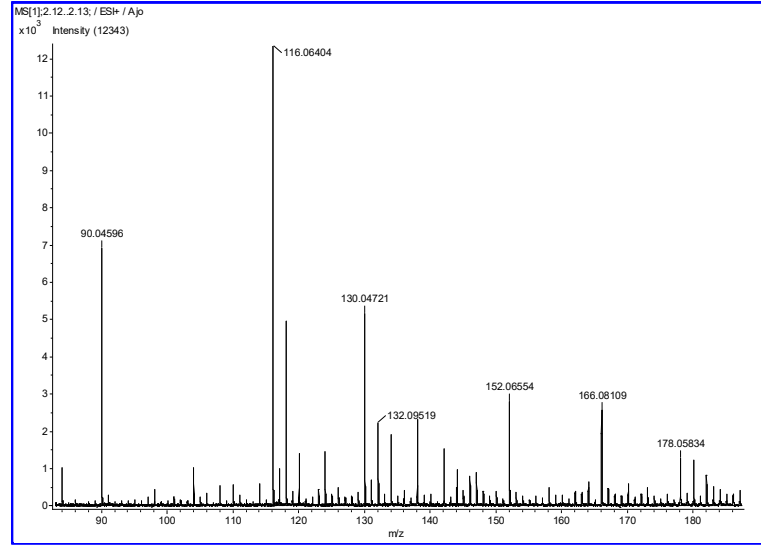

Figure 2. Mass Spectrometry measurement of Garlic Extracts.

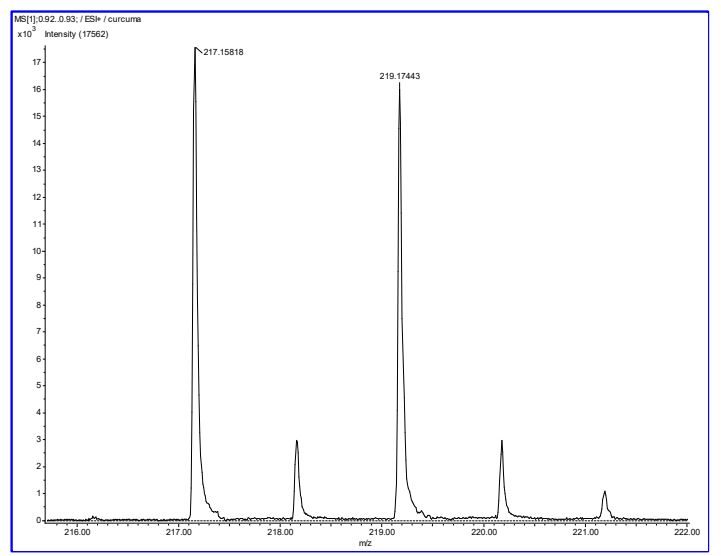

Figure 4. Mass Spectrometry measurement of Turmeric Extracts.

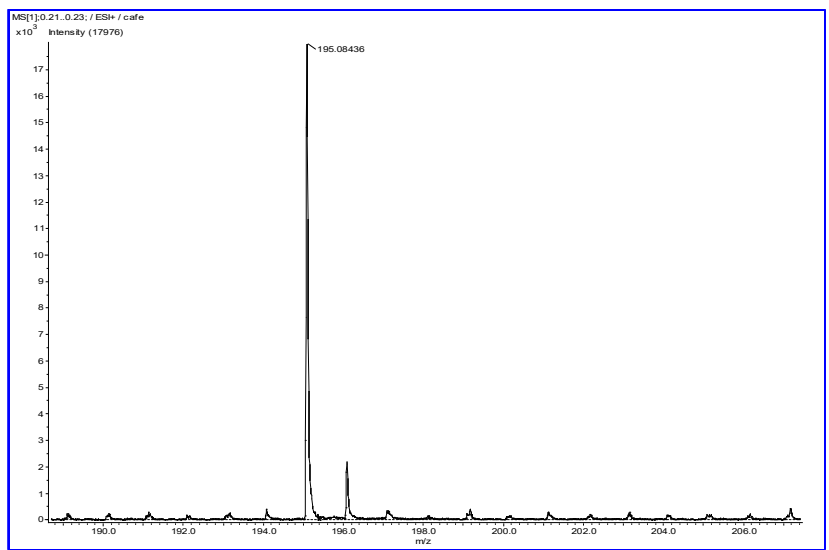

Figure 3. Mass Spectrometry measurement of Coffee extracts.

\begin{tabular}{|c|c|c|c|}
\hline Plants & $\mathbf{m} / \mathbf{z}$ & $\begin{array}{c}\text { Mol. } \\
\text { Formula }\end{array}$ & Compound \\
\hline \multirow{4}{*}{ Garlic } & 116.064 & $\mathrm{C} 5 \mathrm{H} 11 \mathrm{NO} 2$ & Valine \\
\cline { 2 - 5 } & 90.045 & $\mathrm{C}_{3} \mathrm{H}_{7} \mathrm{NO}_{2}$ & Alanine \\
\cline { 2 - 5 } & 130.047 & $\mathrm{C} 6 \mathrm{H} 13 \mathrm{NO} 2$ & leucine \\
& 166.081 & $\mathrm{C} 9 \mathrm{H} 11 \mathrm{NO} 2$ & Phenylalanine \\
\cline { 2 - 5 } Coffee & 178.058 & $\mathrm{C} 6 \mathrm{H} 11 \mathrm{NO} 3 \mathrm{~S}$ & Alliin \\
\hline \multirow{2}{*}{ Turmeric } & 219.084 & $\mathrm{C} 8 \mathrm{H} 10 \mathrm{~N} 4 \mathrm{O} 2$ & Caffeine \\
\cline { 2 - 5 } & 217.158 & $\mathrm{C} 21 \mathrm{H} 20 \mathrm{O} 6$ & Curcumin \\
\hline
\end{tabular}

Table 1. Analyzed compounds from different plant extracts. 